\title{
ALCANCE CONSTITUCIONAL DEL CONFLICTO ENTRE LAS COMUNIDADES INDÍGENAS Y LAS FUERZAS MILITARES EN COLOMBIA ${ }^{1}$
}

\author{
Constitutional Scope of the Conflict between Indigenous Communities \\ and Military Forces in Colombia
}

\section{Delia Constanza Bechara Llanos ${ }^{2}$}

Fecha de Recepción: Noviembre 4 de 2013

Fecha de Aceptación: Noviembre 11 de 2013

SUMARIO: 1. Introducción; 2. Desarrollo; 2.1 Límites y alcances constitucionales de la autonomía de las comunidades indígenas frente al poder de las fuerzas militares colombianas; 2.2 El conflicto de intereses y derechos entre las comunidades indígenas dentro del marco del multiculturalismo y pluralismo que plantea la constitución política; 2.3. La jurisprudencia de la Corte Constitucional y su desarrollo al tópico de los derechos fundamentales de las comunidades indígenas en Colombia; 3. Conclusiones;

4. Referencias bibliográficas.

${ }^{1}$ Este artículo nace como resultado de la propuesta para acceder a la Maestría en Derecho Público de la División de Ciencias Jurídicas de la Universidad del Norte.

${ }^{2}$ Abogada y Especialista en Derecho Administrativo de la Universidad Libre Sede Cartagena. Maestrando en Derecho Público Universidad del Norte. Asesora Jurídica de A.G.M. Desarrollos. 


\section{COMO SE CITA ESTE ARTÍCULO (APA 6)}

Bechara Llanos, D. C. (2014) Alcance constitucional del conflicto entre las comunidades indígenas y las fuerzas militares en Colombia. (Y. Carrillo De la rosa, Ed.) Revista Jurídica Mario Alario D'Filippo, VI (11), pág. 23-35

\section{RESUMEN}

El presente artículo pretende aproximar al lector al debate sobre los derechos fundamentales y las tensiones constitucionales del conflicto entre las comunidades indígenas de Colombia y las fuerzas armadas de este país. Es preciso indicar que la tesis que defenderemos a lo largo del presente documento, es la que determina que ni los derechos de las comunidades indígenas en su órbita de actuación ni los derechos institucionales y soberanos en cabeza de las fuerzas armadas nacionales puede ser vistos como derechos absolutos, y que el conflicto existente entre ambos puede ser conciliable a través de métodos de interpretación constitucional propios del Estado constitucional contemporáneo, como lo es el principio de proporcionalidad.

\section{PALBRAS CLAVE}

Comunidades indígenas, derechos fundamentales, fuerzas armadas de Colombia, tensión, proporcionalidad.

\section{ABSTRACT}

This article aims to bring the reader to the debate on fundamental rights and constitutional tensions of the conflict between the indigenous communities of Colombia and the armed forces of this country. It should be noted that the thesis that we will defend throughout this document, which determines that neither the rights of indigenous communities in its orbit of action nor institutional and sovereign rights at the head of the national armed forces can be seen as rights absolute, and that the conflict between both can be reconciled through alternative methods of constitutional interpretation of contemporary constitutional state, as is the principle of proportionality.

\section{KEYWORDS}

Indigenous communities, fundamental rights, Colombia's armed forces, tension, proportionality. 


\section{INTRODUCCIÓN}

La constitución de 1991 establece un marco pluralista y multicultural de derechos, reconociendo la diversidad étnica y la multiplicidad de culturas que conviven en un territorio al que todos llamamos Colombia. En este sentido, las comunidades indígenas constantemente entran en disputas por la autonomía de sus territorios, con las fuerzas militares del estado colombiano. Lo que en sentido reflexivo nos hace pensar, cuales son los límites y alcances desde el punto de vista constitucional de su autonomía frente al poder legítimo que despliegan las fuerzas armadas en sus territorios. En este contexto, nuestro problema de investigación se estructura de la siguiente manera: ¿Cuáles son los límites y alcances constitucionales de la autonomía de las comunidades indígenas frente al poder de las fuerzas militares colombianas?

Para esto, la autonomía que establece la constitución política frente al ejercicio de los derechos de las comunidades indígenas no puede ser vista como absoluta, ya que frente a este ejercicio de derechos, existen poderes legítimos constituidos como el poder de las fuerzas militares. De conformidad a esto deben indicarse lineamientos que permitan establecer la proporcionalidad de los dos derechos e interés contrapuestos para encontrar un equilibrio razonable a la problemática actual.

Es así que defendemos la pertinencia del presente artículo, ya que cada día más la Constitución política debe adaptarse a los cambios y problemas que vive la sociedad a la cual se dirige, en este contexto existen inclusiones como los derechos de aquellas minorías que deben ser protegidas y respetadas en el marco de la Constitución. Con base en este argumento defendemos la pertinencia de este proyecto de investigación, pues buscamos principalmente, aportar al debate y construir herramientas de inferencia lógica que permitan resolver la problemática planteada. En este orden, es importante indicar, que la investigación se realiza, respondiendo a varios enfoques, ellos son: descriptivo, bibliográfico, explicativo, de tipo cualitativo sobre los límites y alcances constitucionales de la autonomía de las comunidades indígenas frente al poder de las fuerzas militares colombianas. Para esto contrastaremos las principales jurisprudencias de la Corte Constitucional, así como los avances legislativos cobre este régimen especial, para finalmente apoyarnos en estudios de la doctrina nacional.

\section{DESARROLLO}

\subsection{LÍMITES Y ALCANCES CONSTITUCIONALES DE LA AUTONOMÍA DE LAS COMUNIDADES INDÍGENAS FRENTE AL PODER DE LAS FUERZAS MILITARES COLOMBIANAS}

A partir de la Constitución del 91, se abrió una brecha para el reconocimiento de todos los derechos de los ciudadanos, Art. 7 C.P ${ }^{3}$ incluyendo a los derechos de los indígenas, los cuales anteriormente durante la colonia se veían bastante expuestos frente a las autoridades españolas las cuales

\footnotetext{
${ }^{3}$ Art. 7. C.P: El Estado reconoce y protege la diversidad étnica y cultural de la Nación colombiana.
} 
imponían su poderío frente a las clases multirraciales en donde se aplicaban políticas de segregación cultural las cuales eran excesivamente notorias frente a las otras clases sociales, estos eran reconocidos hasta un punto donde no excedieran los derechos ya impartidos, en donde ellos mismos exponían se reconoció sus "usos y costumbres" en tanto no afectara "la ley humana y divina "y el orden económico, político y colonial, luego con la independencia y el inicio del estado liberal, el derecho indiano ${ }^{4}$, dejó de ser reconocido, solo hasta la década de los noventa con la Constitución de 1991, que fueron reconocidos por la diversidad cultural y étnica, y por el pluralismo, identidad cultural que empezaron a tenerse en cuenta los grupos indígenas, la diversidad de cultos por ser un Estado social de derecho, oficializando sus idiomas, costumbres trajes, y promoviendo su cultura, se reconoce el derecho al propio derecho o Derecho consuetudinario y se les dio el reconocimiento como jurisdicción especial ${ }^{5}$,en donde a estos se les dio la facultad de tomar sus propias decisiones judiciales, se les reconoció su propio sistema legal y de derecho, y se habló de una ley constitucional que coordine o sea compatible con esta jurisdicción especial, o las funciones judiciales indígenas con los sistemas nacionales judiciales, que como hemos podido darnos cuenta no se ha visto reflejado en la actualidad.

Se les reconoce una serie de competencias importantes para el desenvolvimiento de las mismas pero a su vez se le limita a la realización de algunas actividades para que no se rompa ese equilibrio social entre las mismas, una competencia territorial y una material, la primera hace referencia al espacio territorial que estos manejan como pueblos o grupos indígenas o de campesinos, pero este debe estar legalmente establecido y la competencia material, se les establece un límite en cuanto a los tipos de sanciones que manejan que no pueden excederse en cuanto a la vulneración de los derechos humanos, la jurisdicción indígena es competente para conocer de cualquier caso que se presente dentro de su territorio, si una persona realiza algún acto contra algún grupo indígena o una comunidad, según la normatividad constitucional este podrá ser juzgado por la comunidad indígena pero como se expuso anteriormente no podrá realizar ningún castigo o penalidad que atente contra los derechos humanos o fundamentales del castigado.

Otros alcances planteados son la de las fuerzas armadas colombianas, las cuales están para garantizar que esos derechos no sean vulnerados, y que no se produzca un estado de guerra, pero en dónde empiezan los derechos de estos y dónde terminan los de las comunidades indígenas. ${ }^{6}$ Las fuerzas Militares (ejército, fuerza aérea, armada), estos en un comienzo empezaron atacando a los insurgentes apoyando y militarizando la zona de campesinos de las guerrillas de ese entonces, realizando obras benéficas para la comunidad, brigadas de salud, y procesos de alfabetización, el enorme aumento de estas se da por que a medida que va pasando el tiempo va creciendo la existencia de grupos guerrilleros y nuevos grupos de delincuencia común, grupos de limpieza social, las bandas

\footnotetext{
${ }^{4}$ El Derecho Indiano es aquel derecho que rigió en la indias occidentales durante el período de la conquista española, fueron leyes promulgadas por los reyes y por otras autoridades subordinadas, estas incluyen el derecho castellano, la costumbre indígena, bulas pontificias, y las capitulaciones entre la corona, es un derecho que tendía a la protección de los indígenas.

${ }^{5}$ Este reconocimiento como jurisdicción especial indígena, consagrado así, desde la Constitución colombiana de 1991, es fuertemente desarrollado desde el derecho comparado, con la propuesta de Ochoa (2002), en: Ochoa, C. (2002). Derecho consuetudinario y Pluralismo jurídico. Primera edición. Cholsamaj, Guatemala. (pp. 89-90)

${ }^{6}$ Convenio 169 de 1989 de la OIT: Límite al derecho de los indígenas a la no vulneración de los derechos humanos o fundamentales, DIH, deberán establecerse procedimientos para la no vulneración de los mismos, y para solucionar los conflictos que se susciten entre las comunidades indígenas y los Derechos humanos.
} 
criminales, que son originadas por la violencia desmedida y las narco guerrillas, haciendo que cada vez más crezca la fuerza pública y trayendo consigo la fuerza desmesurada de las fuerzas militares haciendo que en muchas ocasiones transgredan o vulneren los derechos sin que estos sean afectados activamente pero si de una forma directa, el cual hace énfasis a las siguientes manifestaciones: Incursiones y presencia de grupos armados ilegales en territorios indígenas o cerca de estos, seguido de una fuerte militarización de la fuerza pública.

Ocupación de los lugares sagrados por los grupos armados ilegales y por la fuerza pública. Instalación de bases militares sin consulta previa. Instalación de minas antipersonal, y abandono de municiones sin explotar. La mayoría en comunidades indígenas ${ }^{7}$.

Con esto podemos analizar que las fuerzas militares en el ejercicio de su función pública de servir y garantizar el cuidado de todos los ciudadanos, y en este caso en particular a la comunidades indígenas, y con las manifestaciones anteriormente expuestas nos damos cuenta que no tienen el deber de cuidado y es por esto que estas comunidades están desapareciendo o se están extinguiendo, ya sea que las fuerzas militares no las incluyan activamente en el conflicto, pero por ser sujetos pasivos las están afectando directamente.

Esta situación hizo que la corte constitucional se pronunciara al respecto, en sentencia T-129/11, entrara a debatir el tema de la consulta previa como mecanismo o medio de información, para escuchar sus acuerdos y desacuerdos frente a las medidas de intervención de sus territorios, según el Convenio 169 de la Organización Internacional del Trabajo, hace referencia al Derecho de las comunidades étnicas y principio prohomine ${ }^{8}$, "El principio de interpretación pro homine impone la aplicación de las normas jurídicas que sean más favorables al ser humano y sus derechos; en otras palabras, la imposición de aquella interpretación que propenda por el respeto de la dignidad humana y consecuentemente por la protección, garantía y promoción de los derechos humanos y de los derechos fundamentales contemplados en la Constitución. Este principio está contemplado en los Artículos 10 y 20 Superiores, puesto que en ellos se consagra el respeto por la dignidad humana como fundamento del Estado Social y Democrático de Derecho. Así mismo, es un fin esencial del Estado la garantía de los principios, derechos y deberes consagrados en la Constitución, por parte de todas las autoridades de la República en la protección de todas las personas en su vida, honra, bienes y demás derechos y libertades".

Y por último entramos a hablar acerca de los falsos positivos un tema que se ha venido incrementado, a raíz de todas las situaciones que se presentan por el conflicto armado y que a su vez los más afectados ha sido las comunidades indígenas, por el pie de fuerza y porque en muchas ocasiones "Ios confunden con guerrilleros", y se les señala arbitrariamente de ser colaboradores de las $F A R C$, esto como hemos visto se ha desencadenado, en homicidios, masacres a familias,

\footnotetext{
${ }^{7}$ Auto 004/09 Confrontaciones que se desenvuelven en los territorios indígenas donde intervienen los sujetos activos del conflicto armado afectando directamente a las comunidades indígenas, Magistrado ponente: Manuel José Cepeda Espinosa, sala de revisión segunda de la Corte constitucional, 26 de enero de 2009.

${ }^{8}$ Principio Pro homine: aplicación de normas jurídicas más favorables y menos dañinas al ser humano, respeto a la Dignidad humana en un estado social de derecho, sentencia T- 129/11, Magistrado ponente Jorge Iván Palacio Palacio, 3 de marzo de 2011, Sala quinta de revisión Corte constitucional.
} 
desapariciones forzadas que son mal llamados "falsos positivos", que como expuse anteriormente son dados de baja en combate, por ser presuntos guerrilleros. Con esto se abre una brecha para que pensemos que está sucediendo con nuestras fuerzas militares si están brindando y garantizando un buen servicio a todos los administrados, o si por esta guerra cruenta que ya lleva más de 50 años, estos están perdiendo su norte y se están excediendo en su autoridad.

Analicemos si realmente las fuerzas armadas colombianas tienen o no la razón pero debemos mirarla desde los dos puntos de vista, la de las comunidades indígenas que al ver que se están acabando sus territorios ancestrales, y por el inicio de nuevos mecanismos de destrucción de la sociedad como son las bacrim, por las multinacionales que solo piensan en las ganancias que les va a traer estos grandes hoteles y empresas; y la de las fuerzas militares en la búsqueda de la paz tan anhelada por todos nosotros, han desviado los intereses constitucionales y han excedido su fuerza para acabar con la guerra, llevándose por delante a los más débiles y frágiles como lo son los campesinos, y las comunidades étnicas en todas sus manifestaciones.

\subsection{EL CONFLICTO DE INTERESES Y DERECHOS ENTRE LAS COMUNIDADES INDÍGENAS DENTRO DEL MARCO DEL MULTICULTURALISMO Y PLURALISMO QUE PLANTEA LA CONSTITUCIÓN POLÍTICA}

En la constitución política en su Art. 7: está estipulado que Colombia es un estado pluralista que acepta la diversidad cultural, étnica y religiosa y subsiguiente a este el Art. 8: el cual profesa que el estado debe proteger esta multiculturalidad, garantizando la protección de las riquezas naturales y culturales de la nación, esta multiculturalidad a que hace referencia la Constitución tiene que ver con un sin número de creencias y culturas existentes en nuestra nación, y que estas son de vital importancia para el estado por estar arraigadas a nuestra historia. En nuestro Artículo 330: se dice que la explotación de los recursos naturales ya específicamente en los territorios indígenas se hará sin incurrir en detrimento de la integridad cultural, social y económica de estas comunidades, pero con el auge de la globalización y de las mega construcciones, esto se ha visto quebrantando, principalmente por la misma constitución, aquí observamos entonces un conflicto de intereses entre las comunidades indígenas y el Estado constitucional que está infringiendo una norma constitucional que está por encima de cualquier interés particular.

También nuestra constitución prohíbe cualquier tipo de discriminación a estas comunidades, por los cuales se debe respetar sus creencias, misticismo, divinidad, su forma de vida, la forman en como mantienen el equilibrio de sus pueblos, la religión que estos profesen, y las prácticas que estos utilicen para subsistir ${ }^{10}$.

El estado debe reconocer la titularidad como lo expuse anteriormente de territorios pertenecientes a las comunidades indígenas porque de no realizarse se estaría vulnerado el derecho a la propiedad común, que tenemos todos los ciudadanos, en los casos que se presenten

\footnotetext{
9 Revista semana, "Historia desconocida de los falsos positivos", entrevista a un ex soldado del ejército que dio una entrevista e hizo un relato macabro de esta situación, 11 de junio de 2011.

${ }^{10}$ Sentencia T-601/11 Derechos de los pueblos indígenas o tribales" Derecho de autodeterminación, supervivencia e identidad de los pueblos indígenas, M.P Jorge Iván Palacio Palacio, 10 de agosto de 2011, Sala quinta de Revisión corte constitucional.
} 
conflictos con terceros por posesiones a territorios que pertenecen a las comunidades indígenas, el estado debe entrar como intermediario para resolver este conflicto, por causa de un retardo en la demarcación de esos territorios, o por no haberles entregado a tiempo los títulos de dominio de estos predios.

A su vez en el momento en que se estén realizando los trámites de demarcación y tramitación de títulos de propiedad en estos casos también deben brindarle protección y salvaguardar sus derechos, y a su vez el estado debe abstenerse de todo acto que den lugar a que agentes del propio estado, o terceros intervinientes, afecten el valor, el uso o goce de los bienes de las comunidades indígenas.

Estos presupuestos constitucionales de la diversidad étnica, no se dan en la vida diaria puesto que cada vez observamos cómo estas comunidades son menospreciadas y en ocasiones dejadas a un lado por nuestro estado colombiano, no brindándole los elementos necesarios para que estos subsistan en la sociedad. Pues el multiculturalismo ${ }^{11}$ en el estado es la inclusión y el reconocimiento de la diversidad de intereses e heterogeneidad cultural.

Otro conflicto que se presenta es la disputa entre la posición de las comunidades indígenas en defender sus territorios y sus intereses, y la segunda es la posición de las personas tradicionalistas, esto se ve más reflejado cuando hay algún proyecto de desarrollo económico en el que está incluido las empresas multinacionales, entonces en este punto como lo expuse anteriormente se le debe dar a conocer de esta serie de proyectos a los grupos indígenas por medio de la consulta previa para que estos debatan acerca de lo mejor para sus territorios, en el sentido de que decidan si apoyan o no este proyecto y lo que esto puede ocasionar para el equilibrio forestal y ambiental de los mismos.

Otro punto no menos importante es el conflicto que se genera entre la jurisdicción ordinaria y la jurisdicción especial, a la que hacen parte los indígenas, según el Art. 246: Las autoridades de los pueblos indígenas podrán ejercer funciones jurisdiccionales dentro de su ámbito territorial, de conformidad con sus propias normas y procedimientos, siempre que no sean contrarios a la Constitución y Leyes de la República. La ley establecerá las formas de coordinación de esta jurisdicción especial con el sistema judicial nacional. La sala segunda de revisión de la corte constitucional en sentencia t-009/07 se estudia el conflicto ${ }^{12}$ entre la jurisdicción especial de los indígenas que tienen sus propias autoridades, y que realizan juicios dentro de las mismas comunidades, y la jurisdicción ordinaria esta es la que reside en jueces y tribunales para administrar justicia, y se ejerce sobre todas las personas que no estén sujetas a otra jurisdicción privativa, donde no haya otro juez de conocimiento que conozca de estas. En esta sentencia se habla del fuero que manejan las comunidades indígenas por tener una ley especial: esta maneja unos criterios para determinar la competencia y son los siguientes: uno personal (el miembro de la comunidad

\footnotetext{
${ }^{11}$ Para tener una perspectiva más profunda del concepto multiculturalismo en el campo colombiano observar al menos la propuesta de: Carrillo, Y. (2010). Multiculturalismo diferencias y derechos de las minorías étnicas en la jurisprudencia constitucional colombiana. Primera edición. Ediciones Universidad Libre, Sede Cartagena. (p. 69)

${ }^{12}$ "Efectos jurídicos del conflicto de competencias entre la jurisdicción ordinaria penal y la jurisdicción Indígena un estudio en el resguardo de huellas, Norte del cauca". Lizandro Alfonso Cabrera Suárez, 15 de diciembre de 2011. Pág. 96.
} 
indígena ha de ser juzgado de acuerdo a sus usos y costumbres); 2) geográfico (cada comunidad puede juzgar los hechos que sucedan en su territorio, de acuerdo a sus propias normas). Los anteriores criterios son los que determinan la competencia de jurisdicción indígena. Sin embargo, para que proceda la aplicación de la jurisdicción indígena no es suficiente la constatación de estos dos criterios ya que también se requiere que existan unas autoridades tradicionales que puedan ejercer las funciones jurisdiccionales, la definición de un ámbito territorial en el cual ejercen su autoridad, además de la existencia de usos y prácticas tradicionales sobre la materia del caso y, la condición de que tales usos y prácticas no resulten contrarias a la Constitución o a la Ley. El órgano competente para dirimir estos conflictos es el consejo superior de la judicatura, sala jurisdiccional disciplinaria.

Estos conflictos se presentan por el desconocimiento o ambigüedad de la ley en el sentido que no se sabe diferenciar en qué casos le corresponde conocer a la sala jurisdiccional disciplinaria del consejo superior de la judicatura y cuando a la jurisdicción ordinaria si bien la corte es clara en sus comentarios jurisprudenciales, pero se presentan inconvenientes en el momento en que se presenten conflictos por fuera de los territorios indígenas y el sujeto activo es una persona que esta cobijada con esto fuero especial, que es lo que está sucediendo en el Norte del cauca y si bien se presentan actuaciones en las cuales se envuelven delitos penales, ese sería otro interrogante pues en este caso se enfrentarían la jurisdicción ordinaria penal y la jurisdicción especial indígena, en estos la ley tiene más vacíos en este tipo de acontecimientos, en estos casos la corte entra a hacer estudios de ponderación de principios que entran en juego, para encontrar soluciones veraces y no escapadas de la realidad. Y el juez a su vez debe llenarse de acompañamiento de personas que sean aptas y tengan conocimientos amplios del tema de las comunidades indígenas, por pertenecer está a una norma constitucional como es el pluralismo y la multiculturalidad.

La corte constitucional en su razonamiento amplio, realizando la ley de proporcionalidad y razonabilidad ha estimado, que el derecho consuetudinario prima sobre las disposiciones legales e imperativas siempre que estás primen sobre el principio constitucional a la diversidad cultural y étnica, instituido en nuestra constitución, y propendan por el respeto a los derechos fundamentales de todo ser humano.

\subsection{LA JURISPRUDENCIA DE LA CORTE CONSTITUCIONAL Y SU DESARROLLO AL TÓPICO DE LOS DERECHOS FUNDAMENTALES DE LAS COMUNIDADES INDÍGENAS EN COLOMBIA}

La doctrina jurisprudencial de la corte constitucional ha sido bastante amplia frente al tema de las comunidades indígenas, una de estas es la sentencia T-282/11, comunidades indígenas como sujetos de especial protección constitucional, y titulares de derechos fundamentales. Los cobijan los Art. 7 (Diversidad Étnica), Art. 70 C.P (Principio de igualdad entre culturas), Art. 13 Inc. 1, 2 (1- El estado promoverá las condiciones para que la igualdad sea real y efectiva y adoptará medidas a favor de grupos discriminados y marginados), (2- El estado protegerá especialmente, que por su condición económica, física y mental, se encuentren en circunstancia de debilidad manifiesta y sancionará los abusos o maltratos que contra ellas se cometan). Esto se presenta como un amparo constitucional pues estos grupos indígenas a través de los años han sido marginados y no se les ha brindado el respeto que se merecen, estas personas se encuentran en situación de vulnerabilidad y 
específicamente se han visto afectados por el conflicto armado interno, por esto han buscado mecanismos para apoderarse de sus territorios. Art. 329 C.P: La conformación de las comunidades indígenas se hará en lo estipulado en la ley orgánica de ordenamiento territorial, y esta será delimitada por el gobierno nacional, con el acompañamiento de las comunidades indígenas previo concepto de la comisión de ordenamiento territorial, Art. 330 C.P: De conformidad con la Constitución y las Leyes, los territorios indígenas estarán gobernados, por autoridades indígenas, de acuerdo al uso y costumbres de cada una de estas, está en armonía con el Art. 58 C.P (Derecho a la propiedad colectiva de grupos étnicos sobre territorios) que ordena la protección de todas las formas de propiedad, ya sea privada o colectiva no pueden ser vulneradas por leyes posteriores. Y el Art. 63 C.P: que les atribuye la calidad de inalienables e inembargables a los territorios de los grupos étnicos, tierras de resguardo. Art. 10 C.P: se respeta el dialecto de las comunidades étnicas, estos serán oficiales en sus territorios; Art. 12 C.P: nadie será sometido a desaparición forzada ni torturas, Art. 13 C.P: Derecho a la igualdad, Art. 16 Cp.: Derecho al libre desarrollo de la personalidad, Art. 29 C.P: Derecho al debido proceso, Declaración de las Naciones Unidas sobre los derechos de las comunidades indígenas, el 13 de septiembre de 2007 se le dio reconocimiento a los derechos de los pueblos indígenas aceptados por 143 estados, uno de estos es el derecho a la libre autodeterminación, económica, política, social y cultural, señala que los pueblos y personas de los territorios indígenas tienen derecho a disfrutar de todos los derechos establecidos en el derecho laboral internacional y nacional.

Las comunidades indígenas tienen unos derechos fundamentales ${ }^{13}$ inalienables por el simple hecho de ser seres humanos, el derecho a la vida (Art. 11C.P) es uno de estos según la sentencia T380/93, Derecho a la subsistencia. Derecho a la diversidad étnica están consagrados en la Constitución y en los tratados internacionales, ratificados y firmados por Colombia, según el convenio de la $\mathrm{OIT}^{14}$ y la declaración de las naciones unidas sobre los derechos de los pueblos indígenas ${ }^{15}$, Sentencia T-001/12 Principio del interés superior del niño indígena, esto trata que cuando se presenten conflictos en donde halla presencia de niños indígenas se deben proteger los derechos constitucionales de estos, y a su vez los derechos colectivos como grupo indígena, por la identidad cultural y étnica que poseen estos, instituidos en esta sentencia por el principio proinfans, estos se han venido reconociendo por el tema de niños, niñas y adolescentes, y estos deben ser resueltos por autoridades que manejen sus mismos usos y costumbres.

La Sentencia T-601/11, también nos habla de los derechos fundamentales de la comunidad indígena, Derecho de la autonomía de los pueblos indígenas, Prohibición de tortura, la prohibición a la esclavitud, Principio de legalidad, estos son limitantes a la autonomía de la libertad por pertenecer a una jurisdicción especial, sentencia C-151/03, los indígenas que administren recursos del estado serán disciplinados conforme a la Ley 734/02, Art. 25, Sentencia C- 864/08, derechos fundamentales de los pueblos indígenas en su condición de sujetos colectivos. "Los derechos de las comunidades indígenas no deben ser confundidos con los derechos colectivos de otros grupos

\footnotetext{
${ }^{13}$ Marco legal para los Derechos de los pueblos indígenas en Colombia. Vemund Olsen, primera edición, octubre de 2008 Pág $14,15$.

${ }^{14}$ Convenio OIT, N .169 , Organización internacional del trabajo, adoptado en 1989.

${ }^{15}$ Declaración de las Naciones Unidas sobre los Derechos de las comunidades Indígenas, 29 de junio de 2006.
} 
humanos, cada comunidad indígena es un sujeto colectivo y no una sumatoria de individuos particulares que comparten una serie de derechos o intereses diferentes. Además de esto también le concedió el derecho y acceso a los servicios de salud en Colombia, con la Ley 691 de $2001^{16}$, estos participaran como afiliados al sistema subsidiado en salud, con excepciones en algunos casos estipulados en esta ley.

Sentencia T-001/94, Intereses colectivos, sentencia SU-510/98, Derecho a la diversidad étnica, protección de los derechos fundamentales, Sentencia T-342/94 protección cultural de los "NUKAKMAKU", identidad cultural uso de la lengua nativa, la corte constitucional declaro exequible el Art. 42 de la Ley 47 de $1993^{17}$, que nos habla acerca de que en las regiones del país que cuentan con una lengua local o nativa, se deben proteger la riqueza cultural, y esta debe hacerse con su lengua materna, la negativa de que el estado no propenda esto o no le dé la importancia que se merece se estaría violando el derecho a la igualdad al discriminar sus expresiones lingüísticas legítimas, si bien consagra la constitución un idioma oficial que debe ser utilizado por todos los colombianos, que es el español , reconoce y acepta en su Artículo 10 "que las lenguas y los Dialectos de los grupos étnicos son también oficiales en sus territorios".

Sentencia T-428/92, otro derecho de suma importancia para las comunidades Indígenas, es habitar en un ambiente sano, esto quiere decir ya sea por las obras realizadas en los terrenos indígenas, esto no quiere decir que por esto, su tierra sufra daños irremediables, estos perjuicios deben ser previsibles, en cuanto debe hacerse un estudio del terreno, en cuanto las obras civiles no deben hacer omisión frente a estas situaciones. Otras sentencias de mucha importancia y riqueza constitucional en temas de comunidades indígenas serían las Sentencias T-973/09, Sentencia SU039/97, C-530/93.

Finalmente los territorios indígenas gozan de herramientas constitucionales de defensa, creados a partir de la Constitución de 1991, para el preservar de sus pueblos y que estos no desaparezcan por asuntos ajenos a estos como la Guerra en Colombia, que cada vez más los está afectando, sus territorios son respetados por los principios y normas constitucionales, y también por los tratados constitucionales ratificados por Colombia, aprobados por el congreso de la República con otros países, y también por el principio pro homine como lo expuse anteriormente el cual especifica que las normas han de complementarse de manera que siempre se amplié la protección de estas normas en el ordenamiento jurídico interno y no se disminuya en cuanto la norma que se desprende del tratado internacional, sea más restrictiva.

El pluralismo estipulado en el Art. 1 de la C.P "Colombia es una república unitaria, descentralizada, con autonomía de sus entidades territoriales, democrática, participativa y pluralista" permite una multiplicidad de cultura y se les da una protección a la Diversidad étnica, Autonomía jurídica de escoger sus entes territoriales, se les brinda una protección y un blindaje jurídico.

\footnotetext{
${ }^{16}$ Ley 691/2001 “Participación de los grupos étnicos al sistema de seguridad social colombiano" Secretaria del Senado de la República, Diario Oficial 44558 del 21 de septiembre de 2001.

${ }^{17}$ Ley 47 del 93 Art. 42: idioma y lengua oficial en el departamento de san Andrés y Santa Catalina, el castellano y el inglés comúnmente hablado por las comunidades nativas del archipiélago.
} 


\subsection{PRECISIONES FINALES FRENTE AL PRINCIPIO DE AUTONOMÍA DE LOS PUEBLOS INDÍGENAS}

Nos hemos podido dar cuenta que las comunidades Indígenas, están perdiendo su identidad y sobre todo están siendo sujetos de vejámenes tanto por los actores del conflicto armado(Farc, ELN, Narco guerrillas, Bacrím etc.) como por la fuerza pública (policía, ejército, fuerzas armadas), no han podido estos gozar efectivamente de todos los Derechos Fundamentales estatuidos en nuestra Carta Política, analizamos las formas de solucionar los conflictos que se presenten entre estos, pero hay que buscar mejores mecanismos para llegar a un equilibrio social.

Además porque los territorios Ancestrales están desapareciendo por las malas decisiones de los gobernantes, solo por pensar en los intereses particulares y no generales y específicamente de estas comunidades que no están siendo respetados, a su vez el principio de proporcionalidad, en estos casos si sería un mecanismo eficiente para el conflicto entre estas dos partes, pero deben intervenir en estos procesos personas que tengan los conocimientos aptos para la resolución de estas tesis, pues en muchas ocasiones intervienen personas no aptas y esto lo que hace es seguir atrasando el proceso de consolidación al arreglo inmediato de esta problemática, y sobretodo respetando ambos jurisdicciones especiales, tanto la indígena como la de las fuerzas militares, pero ante todo se debe reconocer la realidad de esta situación, pues está todavía no ha sido aceptada por nuestros gobernantes, o por las autoridades encargadas de preservar y proteger a los pueblos indígenas, este es un problema más grave de lo que pensamos y si le damos larga a esto, seguiremos afectando a la parte más débil del conflicto que son las comunidades indígenas, y que de uno u otra manera son ajenos a esta. El estado de temor en los que viven cotidianamente y que estas situaciones se repitan o empeoren, $y$ al encontrarse en una desesperanza por que el estado no ha entrado como garante y protector de sus derechos han hecho que estos se vuelvan más violentos y busquen por así decirlo tomarse las vías de hecho ante esta situación que los persigue diariamente y que a lo único que los ha llevado es al Desplazamiento forzado, a perder sus territorios, a la mendicidad total y a la absoluta pobreza.

Y También los grupos indígenas no confían en las fuerzas militares, por la misma desconfianza que les ha proporcionado las autoridades competentes, o el gobierno nacional, en su autoridad desmedida por buscar intereses a título personal y dejar a un lado los intereses de estas comunidades que están siendo vulnerados.

\section{REFERENCIAS BIBLIOGRÁFICAS}

CABRERA, L. (2011) “Efectos jurídicos del conflicto de competencias entre la jurisdicción ordinaria penal y la jurisdicción Indígena un estudio en el resguardo de huellas, Norte del Cauca". En: Justicia Juris, Vol. 7. № 2. Julio-Diciembre. pp. 93-106.

CARRILLO, Y. (2010) "Multiculturalismo diferencias y derechos de las minorías étnicas en la jurisprudencia constitucional colombiana". Editorial Universidad Libre Sede Cartagena. Cartagena, Colombia.

OLSEN, V. (2008) “Marco legal para los Derechos de los pueblos indígenas en Colombia”. Editado por: Human Rights Everywhere \& Organización Nacional Indígena de Colombia, Octubre. Bogotá, Colombia. 


\section{JURISPRUDENCIA CITADA}

CORTE CONSTITUCIONAL, Sentencia C-578 de 2002. Magistrado Ponente: Manuel José Cepeda Espinosa. CORTE CONSTITUCIONAL, Sentencia C-1056 de 2004. Magistrada Ponente: Clara Inés Vargas Hernández. CORTE CONSTITUCIONAL, Sentencia C-187 de 2006. Magistrada Ponente: Clara Inés Vargas Hernández. Corte Constitucional, Sentencia C-587 de 1992. Magistrado Ponente: Ciro Angarita Barón. CORTE CONSTITUCIONAL, Sentencia T-011 de 1992. Magistrado Ponente: Alejandro Martínez Caballero.

CORTE CONSTITUCIONAL, Sentencia T-342 de 1994. Magistrados ponentes: Antonio Barrera Carbonell, Eduardo Cifuentes Muñoz, Carlos Gaviria Díaz.

CORTE CONSTITUCIONAL, Sentencia SU-510 de 1998. Magistrado ponente: Eduardo Cifuentes Muñoz.

CORTE CONSTITUCIONAL, Sentencia T-001 de 1994. Magistrado ponente: José Gregorio Hernández Galindo.

CORTE CONSTITUCIONAL, Sentencia T-380 de 1993. Magistrado ponente: Eduardo Cifuentes Muñoz.

CORTE CONSTITUCIONAL, Sentencia C-864 de 2008. Magistrado Ponente: Marco Gerardo Monroy Cabra.

CORTE CONSTITUCIONAL, Sentencia C-151 de 2003. Magistrado ponente: Rodrigo Escobar Gil.

CORTE CONSTITUCIONAL, Sentencia T-601 de 2011. Magistrado ponente: Jorge Iván Palacio Palacio.

CORTE CONSTITUCIONAL, Sentencia T-002 de 2012. Magistrado ponente: Juan Carlos Henao Pérez.

CORTE CONSTITUCIONAL, Sentencia T-428 de 1992. Magistrado ponente: Ciro Angarita Barón.

CORTE CONSTITUCIONAL, Sentencia SU-510 de 1998. Magistrado Ponente: Eduardo Cifuentes Muñoz.

CORTE CONSTITUCIONAL, Sentencia T-282 de 2011. Magistrado Ponente: Luis Ernesto Vargas Silva.

CORTE CONSTITUCIONAL, Sentencia T-129 de 2011. Magistrado Ponente: Jorge Iván Palacio Palacio.

CORTE CONSTITUCIONAL, Sentencia T-009 de 2007. Magistrado Ponente: Manuel José Cepeda Espinosa.

CORTE CONSTITUCIONAL, Auto 004 de 2009. Magistrado ponente: Manuel José Cepeda Espinosa.

CORTE CONSTITUCIONAL, Sentencia C-241 de 2010. Magistrado Ponente. Juan Carlos Henao Pérez.

CORTE CONSTITUCIONAL. Sentencia T-945 de 2001, Magistrado Ponente. Manuel José Cepeda Espinosa.

CORTE CONSTITUCIONAL, Sentencia, T-1091 de 2005. Magistrado Ponente. Clara Inéz Vargas Hernández. 
CORTE CONSTITUCIONAL, Sentencia C-383 de 1999. Magistrado Ponente. Alfredo Beltrán Sierra.

REVISTA SEMANA. "Historia desconocida de los falsos positivos". Entrevista a un ex soldado del ejército, 11 de junio de 2011.

\section{NORMAS INTERNACIONALES}

CONVENIO 169 DE 1989 DE LA OIT: Límite al derecho de los indígenas a la no vulneración de los derechos humanos o fundamentales y DIH.

DECLARACIÓN DE LAS NACIONES UNIDAS sobre los Derechos de las comunidades Indígenas, 29 de junio de 2006. 